\title{
Noninvasive Determination of the Amount of Ethanol in Liquid Mixtures by Ultrasound Using Bilinear Interpolation Method
}

\author{
Ahmet Aydın ${ }^{1 *}$, Cemil Keskinoğlu ${ }^{1}$, Umut Kökbaş$^{2}$, Abdullah Tuli ${ }^{3}$ \\ ${ }^{1}$ Department of Biomedical Engineering, Cukurova University, Adana, Turkey. \\ ${ }^{2}$ Department of Medical Biochemistry, University of Kyrenia, Girne, Cyprus. \\ ${ }^{3}$ Department of Medical Biochemistry, Cukurova University, Adana, Turkey.
}

*Corresponding author: Ahmet Aydın, email: $\underline{\text { aaydin@cu.edu.tr }}$

Received August 5 ${ }^{\text {th }}, 2018$; Accepted June 21 ${ }^{\text {th }}, 2019$.

DOI: http://dx.doi.org/10.29356/jmcs.v64i1.1031

\begin{abstract}
Ultrasound is used in many analysis studies, including liquid mixtures. Many mixtures are analyzed to understand their contents or properties in different situations. One of these mixtures is the ethanol-water combination. In this study, the amount of ethanol in the liquid mixture was determined noninvasively by the ultrasonic method using a microcontroller-based system. The results show that the measurements obtained were within the $p<0.05$ confidence interval. The characteristics evaluation of the system shows that the system can detect ethanol concentration as low as $0.552 \mathrm{~g} / \mathrm{L}$, thus the system has a broad and linear determination range for ethanol. Although the system is calibrated and tested with ethanol-water mixture, it can be used for any mixture that changes density related to the substance concentration, including different alcohols which are soluble in water (glycols, glycoethers, etc.) or any other material (solid or liquid) which is soluble in alcohol or different liquid solvent. The system has so many advantages that make it possible to use comfortably in many areas where the amount of ethanol contained in the mixture is essential. These advantages are the high accuracy and sensitivity, being noninvasive, portable, and not having a destructive effect on the substance.
\end{abstract}

Keywords: TOF measurement; bilinear interpolation; noninvasive ultrasonic method; mixture analysis, alcohol concentration.

Resumen. El ultrasonido es utilizado en muchos estudios incluyendo las mezclas liquidas. Se analizan varias mezclas para entender sus contenidos y propiedades en diferentes situaciones. Una de estas mezclas es la combinación de etanol-agua. En este estudio, la cantidad de etanol en la mezcla líquida fue determinada de manera no invasiva con el método ultrasonico utilizando un sistema basado en microcontrolador. Los resultados muestran que las mediciones obtenidas se encontraban dentro de un intervalo de confianza de $p<0.05$. Las características de evaluación del sistema muestran que se puede detectar etanol a una concentración tan baja como $0.552 \mathrm{~g} / \mathrm{L}$, por lo tanto, el sistema tiene un rango de determinación linear amplio para etanol. Aunque el sistema se calibra y prueba con mezcla de etanol-agua, puede ser utilizado para cualquier mezcla que cambia de densidad en relación con la concentración de la substancia, incluyendo diferentes alcoholes que son solubles en agua (glicoles, glicoeteres, etc) o cualquier otro material (sólido o líquido) que sea soluble en alcohol o en algún solvente líquido diferente. El sistema tiene muchas ventajas que hacen posible su utilización en muchas áreas donde la cantidad de etanol contenida en la mezcla es esencial. Estas ventajas son de alta precisión y sensiblididad al ser no invasivo, portátil y al no tener un efecto destructivo sobre la sustancia.

Palabras clave: Medición del TOF; interpolaciòn bilinear; método ultrasonico no invasivo; análisis de mezclas; concentración de alcohol. 


\section{Introduction}

Ultrasound technologies have become increasingly widespread in many areas. One of these is using ultrasonic velocity measurements to analyze the contents of the mixture [1-7]. The determination of the changes in the number of substances and the amount of each substance contained in the solution is of great importance to monitor the processes, analyze the solution, and determine the contents of foods or mixtures. Measurement of sound velocity and density in the mixtures is also essential in understanding molecular interactions [8].

Ethanol is a water-soluble organic molecule. This feature of ethanol allows it to be used intensively many processes in the industry such as pharmaceutical, food, beverage, cosmetics, paint, medical, and automotive. Ethanol also being used in medicines and also have clinical importance. Its analysis is also essential in the diagnosis and treatment of some disorders (alcohol toxicity, brain trauma, uremia, diabetes acidosis, behavior) $[9,10]$. Also, it is very important to determine the amount of ethanol in the mixture precisely because the liquid-ethanol mixture is used in the calibration of ultrasonic systems and in some cases the results of the theoretical approach in determining the substance contents do not correspond with the results obtained in the practical study.

Liquid alcohol-water mixtures show unusual properties when the amount of water is high in the mixture. These are usually explained by the molecular relationship leading to cluster formation. Only in some cases; the concentration dependencies of molar heat capacity, partial molar volumes, mixture heat, and sound velocity show substantial deviations from the behavior of ideal systems. While the speed of sound in pure water and pure ethanol is dependent on temperature, in mixtures, the speed is also dependent on the composition of the mixture $[11,12]$.

The determination of the amount of alcohol in biological liquids was carried out for the first time in $20^{\text {th }}$ century, and then it was modified by many researchers [13]. Nowadays, in addition to enzymaticspectrophotometric based methods for the determination of alcohol, chromatographic, physical-biologicalchemical sensor systems are also used extensively [14-16]. Sensor-based methods have a significant advantage over other methods and more preferred for their specificity, quick response, and no need for expensive equipment [17].

In the literature, previous studies were performed using ultrasonic methods in the measurements of ethanol-water mixtures. Meister measured the sound velocity of pure water, pure ethanol and their mixtures with an ultrasonic echometer operating at $4 \mathrm{MHz}$ [12]. Martin and Spinks studied several ethanol/water mixtures and measured the speed of sound in liquid with an accuracy of $\% 0.1$ by controlling the temperature with $1^{\circ} \mathrm{C}$ precision [18]. Tong et al. measured speed of sound and density of mixture across the range 10 to $50^{\circ} \mathrm{C}$ with an ultrasound resonator and a densitometer [19].

There are different analysis methods such as hydrometers or digital density meter and expensive analyzers such as gas chromatography for the determination of ethanol [20-22]. All these methods, except ultrasonic technique, are invasive analysis methods. The other studies used ultrasound for analysis use large and expensive lab equipment for the measurement [23-25].

In this study, the ethanol mixture is analyzed noninvasively with only one portable integrated ultrasonic system without the need for any other device such as oscilloscope, signal generator etc. The noninvasive analysis is important since it can be applied quickly and does not have any destructive effect on the sample. Having an integrated system for the measurement gives an advantage in terms of cost, portability, and ease of use. In this study, a practical approach has been developed to determine alcohol concentration rapidly with high accuracy in liquid mixtures. Since the density of the alcohol in the environment is highly correlated with the ambient temperature, problems may arise in the accuracy of the measurements if the system is not calibrated regarding the temperature. For a more reliable measurement, several liquid mixtures were prepared and analyzed with distilled water and ethanol. For the analysis, ultrasound signal was generated by a microcontroller, and then this ultrasonic signal was applied to the liquid mixture in a container using a piezoelectric transducer. Since the distance of the container where the ultrasonic signal is propagated is constant, the sound speed can be calculated from the measured time of flight (TOF) of the ultrasound wave. In this study, the TOF values are measured, and the change in these values was analyzed to find the amount of ethanol in the mixture utilizing the interpolation method. 


\section{Theory}

The sound is a mechanical wave. Therefore, it needs a medium to propagate. As the sound wave is influenced by the changes in the propagation environment, a change in the TOF is evaluated and used to analyze the properties of the environment, such as temperature, density, and pressure.

The formula used for the speed of sound at compressible fluids, including liquids is given in Eq. 1.

$$
c=\sqrt{\frac{\beta}{\rho}}
$$

In this formula, $c$ is the sound speed, $\beta$ is the Bulk module, i.e., the inverse of compressibility, and $\rho$ is the density of the medium. As seen from the formula, a change in the density causes a change in sound velocity [26]. Depending on the change at speed, the measured TOF will change as well.

The time elapsed between the generation of the sound wave by the transmitter piezo disc and its detection by receiver piezo disc is called time of flight (TOF). In this study, a single piezoelectric ceramic disc transducer is used for both the production and detection of the sound wave. This principle is called the pulseecho principle and it is the event that the ultrasonic wave produced by the piezoceramic is reflected back from a certain surface, and the same piezoelectric transducer detects this reflected sound wave. According to this principle, the TOF value is calculated according to Eq. 2.

$$
T O F=\frac{2 . d}{c}
$$

where $d, c$, and TOF represent the width of the container, the propagation speed of the sound wave in the medium, and time of flight, respectively. Since single piezo is used for both creating and sensing of the sound wave, the total distance will be $2 d$. When measuring TOF, firstly a start wave is generated to create the ultrasonic wave, and then a stop wave is created when the echo above a certain threshold level is detected. The time between the start wave and stop wave gives the TOF. The system can measure TOF in nanosecond precision. The oscilloscope image of start wave, stop wave, and echo together with stop wave is shown in Fig.1.

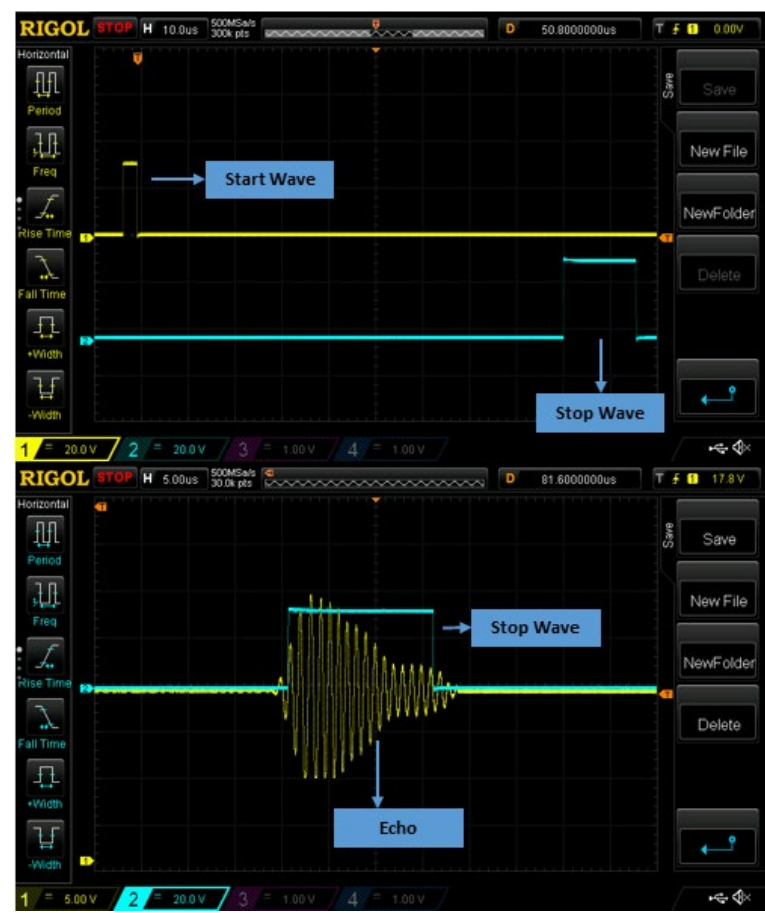

Fig. 1. The oscilloscope images of start, stop, and echo waves. 
Since the density of the liquid mixture and consequently the TOF value depends on temperature and ethanol concentration, the bilinear interpolation method was used to determine the amount of ethanol for unmeasured intermediate temperatures and concentrations.

For bilinear interpolation, linear interpolation is applied on both $x$ and $y$-axes which represents temperature and TOF values (Fig. 2). The $A_{11}, A_{12}, A_{21}, A_{22}$ in Fig.2 represent the TOF values measured during calibration of the system at a known concentration and temperature values, and $T$ is the value should be determined at an intermediate temperature and concentration which is not measured previously.

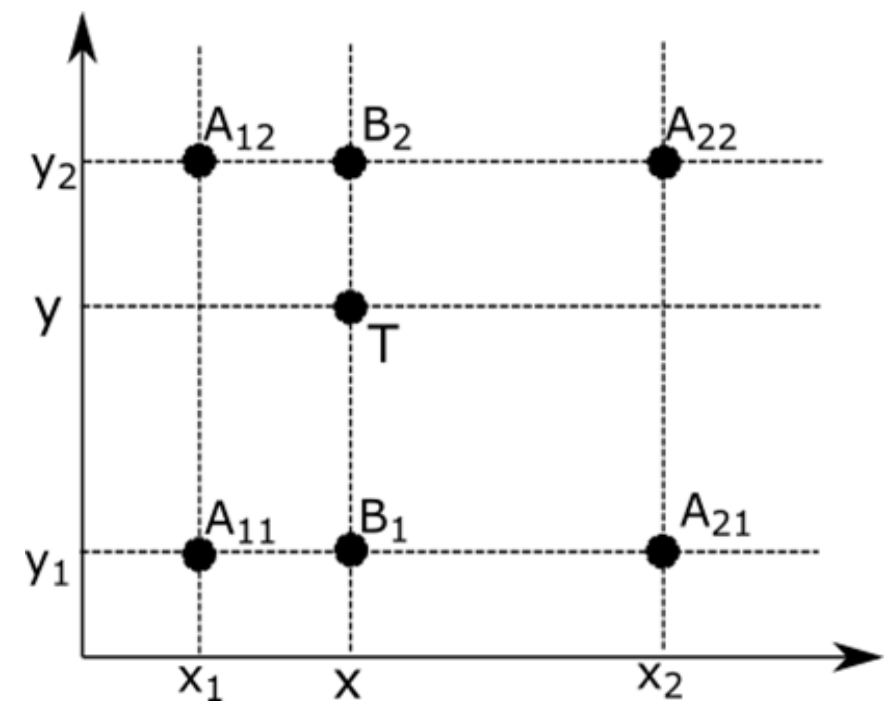

Fig. 2. Bilinear interpolation graph.

The steps or the bilinear interpolation are as follows: firstly, linear interpolation is applied on the $x$-axis with Eq.3 and Eq.4 to find the values of $B_{1}$ and $B_{2}$ on Fig. 2 ,

$$
\begin{aligned}
& f\left(x, y_{1}\right)=f\left(B_{1}\right)=\frac{x_{2}-x}{x_{2}-x_{1}} f\left(A_{11}\right)+\frac{x-x_{1}}{x_{2}-x_{1}} f\left(A_{21}\right) \\
& f\left(x, y_{2}\right)=f\left(B_{2}\right)=\frac{x_{2}-x}{x_{2}-x_{1}} f\left(A_{12}\right)+\frac{x-x_{1}}{x_{2}-x_{1}} f\left(A_{22}\right)
\end{aligned}
$$

and then on the $y$-axis with Eq.5 to find the value of $T$ on Fig. 2 which represents TOF value for an unmeasured temperature and concentration.

$$
f(x, y)=f(T)=\frac{y_{2}-y}{y_{2}-y_{1}} f\left(B_{1}\right)+\frac{y-y_{1}}{y_{2}-y_{1}} f\left(B_{2}\right)
$$

When the Eq. 5 is examined, it is seen that this equation is related to $f\left(B_{1}\right)$ and $f\left(B_{2}\right)$ in Eq. 3 and 4. When these two functions, are substituted in Eq.5, $f(x, \mathrm{y})$ given in Eq. 6 is obtained [27].

$$
\begin{aligned}
f(x, y)=f(T)= & \frac{y_{2}-y}{y_{2}-y_{1}}\left(\frac{x_{2}-x}{x_{2}-x_{1}} f\left(A_{11}\right)+\frac{x-x_{1}}{x_{2}-x_{1}} f\left(A_{21}\right)\right) \\
& +\frac{y-y_{1}}{y_{2}-y_{1}}\left(\frac{x_{2}-x}{x_{2}-x_{1}} f\left(A_{12}\right)+\frac{x-x_{1}}{x_{2}-x_{1}} f\left(A_{22}\right)\right)
\end{aligned}
$$


By solving Eq.6, final definition of bilinear interpolation is obtained as given in Eq. 8

$$
\begin{gathered}
f(x, y)=\frac{1}{\left(x_{2}-x_{1}\right)\left(y_{2}-y_{1}\right)}\left(f\left(A_{11}\right)\left(x_{2}-x\right)\left(y_{2}-y\right)+f\left(A_{21}\right)\left(x-x_{1}\right)\left(y_{2}-y\right)\right. \\
\left.+f\left(A_{12}\right)\left(x_{2}-x\right)\left(y-y_{1}\right)+f\left(A_{22}\right)\left(x-x_{1}\right)\left(y-y_{1}\right)\right) \\
f(x, y)=f(T)=\frac{1}{\left(x_{2}-x_{1}\right)\left(y_{2}-y_{1}\right)}\left[\begin{array}{ll}
x_{2}-x & x-x_{1}
\end{array}\right]\left[\begin{array}{ll}
f\left(A_{11}\right) & f\left(A_{12}\right) \\
f\left(A_{21}\right) & f\left(A_{22}\right)
\end{array}\right]\left[\begin{array}{l}
y_{2}-y_{1} \\
y-y_{1}
\end{array}\right]
\end{gathered}
$$

The student t-test was used to check the relevance of the results by testing if there is a statistically significant difference between the variables, or the observed average value is different from the default values. This test is also known as a small sample testing technique since can be applied when $n<30$ or in cases where the mean of the average mass is suspected to be normal [28]. The formula of the test is given at Eq. 9., where $\mu, s$ are the mean and variance of the sample respectively, and $n$ is number of samples [29].

$$
t=\frac{\mu_{1}-\mu_{2}}{s_{p}{ }^{2} \sqrt{\frac{1}{n_{1}}+\frac{1}{n_{2}}}}
$$

\section{Experimental}

In this study, the amount of ethanol in the liquid mixture was determined by measuring TOF [30]. The measurement data is obtained by firstly putting $200 \mathrm{ml}$ pure water into a container and then adding $70^{\circ}$ ethanol with $0.2 \mathrm{ml}$ steps until $5 \mathrm{ml}$. For each ethanol concentration, the temperature has been changed from $296 \mathrm{~K}$ to $308 \mathrm{~K}$ with one-kelvin steps. And the measurements are done for all concentration and temperature combinations. Therefore 338 measurement data points are obtained from 26 different concentrations at 13 different temperatures. For the temperature control, a water bath with $+/-0.1^{\circ} \mathrm{C}$ temperature stability is used. The dimensions of the container are $72 \times 95 \mathrm{~mm}$, and wall thickness is $1 \mathrm{~mm}$. For the transducer, a $1 \mathrm{MHz}$ piezoelectric ceramic disc with $20 \mathrm{~mm}$ diameter and shielded cable is used.

The transducer is glued to the acrylic container from the outer corner with a special cyanoacrylate adhesive to ensure the high propagation of the ultrasound wave. Before gluing the transducer, the surface is sanded to increase the adhesion. For the measurements TI TDC1000 - TDC7200EVM is used and system controlled with the onboard TI MSP430F5528 microcontroller [31]. For the data acquisition, a LabVIEW GUI and for the analysis MATLAB is used. The block diagram of the system is given in Fig. 3.

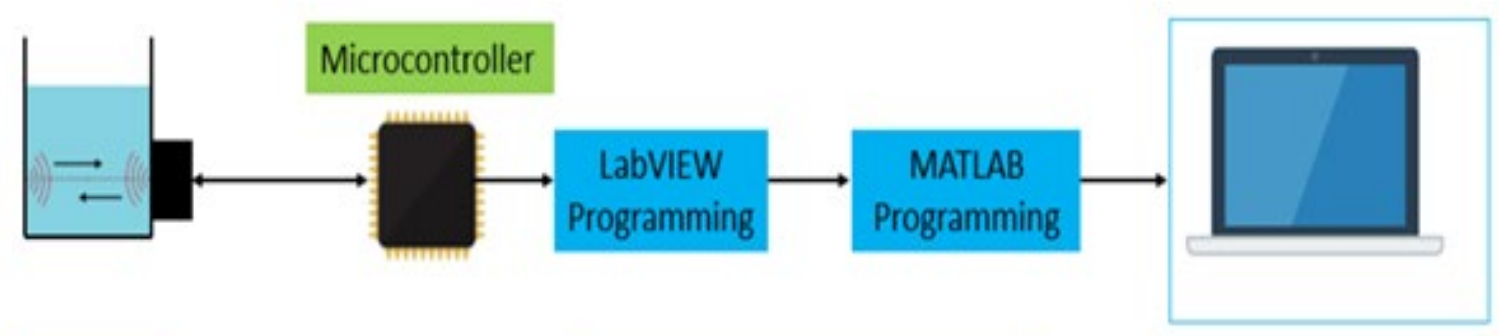

\section{Container}

Fig. 3. Block diagram of the system. 
TI TDC1000 - TDC7200EVM is a module that can generate and receives ultrasonic waves then find the TOF in nanoseconds. The module has a GUI for parameter settings and data acquisition. It can be configured to work in 3 different modes: Mode 0 for level and fluid identification using 1 piezo transducer, Mode 1 for single one direction TOF measurement and, Mode 2 for water flow metering applications [32]. The module has two measurement channels and each channel can be configured to use one or two different piezo for TOF measurements, Fig 4.

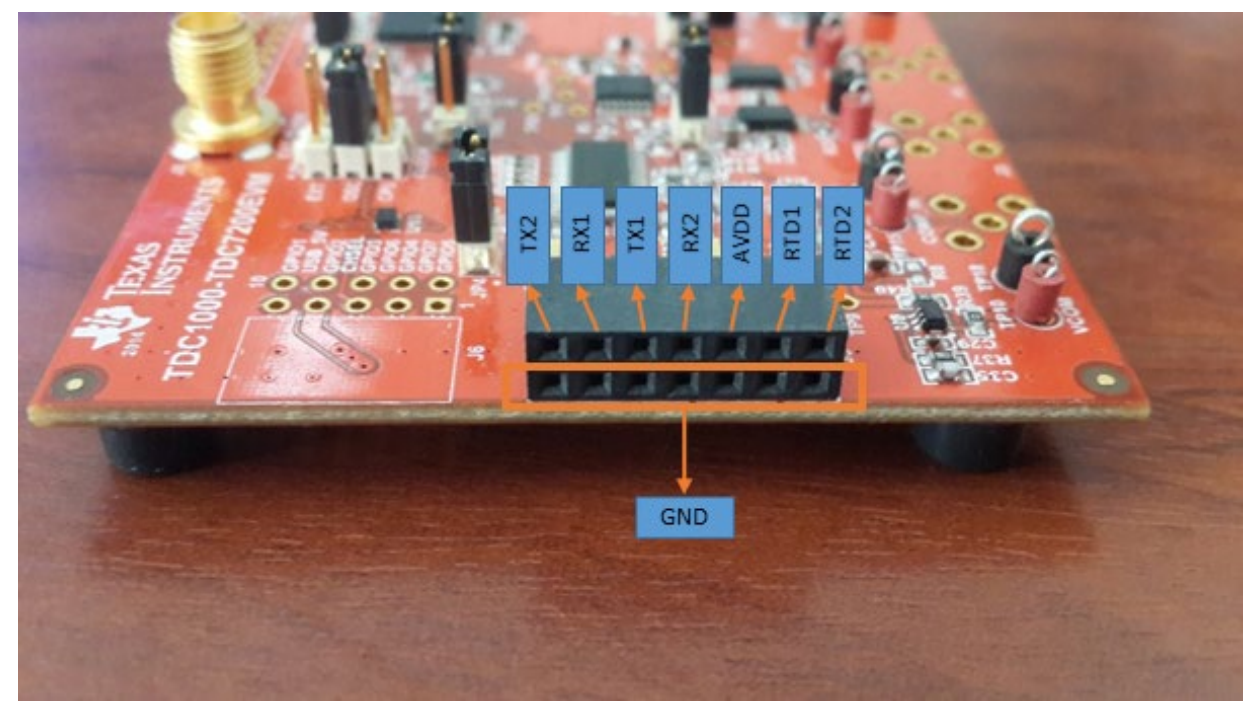

Fig. 4. TDC1000-TDC7200 EVM pinout. TX1, RX1 and TX2, RX2 are transmitter and receiver transducers of channels one and two, respectively. AVDD is system power pin and finally RTD1, RTD2 are temperature sensor pins.

Since one piezo is used at channel two for TOF measurement, TOF_MEAS_MODE register is configured as Mode 0, MEAS_MODE register as TOF measurement, and the CH_SEL register as CH2, Fig. 5.

\begin{tabular}{|c|c|c|c|c|c|c|c|c|c|c|c|c|c|}
\hline \multirow{2}{*}{\multicolumn{2}{|c|}{$\begin{array}{l}\text { CONFIGO (OXOO) } \\
\text { TX_FREQ DIV }\end{array}$}} & & \multirow{2}{*}{\multicolumn{3}{|c|}{$\begin{array}{l}\text { CONFIG1 (OX01) } \\
\text { NUM_AVG }\end{array}$}} & \multicolumn{4}{|c|}{ CONFIG2 (0X02) } & \multirow{2}{*}{\multicolumn{2}{|c|}{ DAMPING }} & \multirow{2}{*}{\multicolumn{2}{|c|}{ CH_SWP }} \\
\hline & & & & & & VCOM_SEL & & MEAS_MODE & & & & & \\
\hline Divide by 8 & v & & 1Cycle & v & & Internal & v & TOF Measurement & $v$ & Disabled & $v$ & Disabled & $v$ \\
\hline \multicolumn{3}{|l|}{ NUM_TX } & \multicolumn{3}{|l|}{ NUM_RX } & \multicolumn{2}{|l|}{ EXT_CHSEL } & CH_SE & & \multicolumn{2}{|c|}{ TOF_MEAS_MODE } & & \\
\hline 5Pulses & v & $R$ & No RX Event Count & v & $R$ & Disabled & $v$ & $\mathrm{CH} 2(\mathrm{~T} \times 2)$ & v & Mode 0 & v & $R$ & \\
\hline
\end{tabular}

Fig. 5. TDC1000-TDC7200EVM GUI Parameter Setting.

\section{Results and discussion}

All the TOF measurements used in the study are given in the Appendix as Tables 1 . The TOF graph at different temperatures of different concentrations after interpolation is given in Fig 6. Each plot in the graph represents the amount of ethanol in $0.2 \mathrm{ml}$ increments from $0 \mathrm{ml}$ to $5 \mathrm{ml}$. From the graph in Fig. 6, it is clearly seen that the TOF values change due to the increase in the amount of ethanol in the mixture and temperature. 
Table 1. Measured TOF values $(296-308 \mathrm{~K})$.

\begin{tabular}{|c|c|c|c|c|c|c|c|c|c|c|c|c|c|}
\hline Ethanol(ml) & \multicolumn{13}{|c|}{ Kelvin(K) } \\
\hline & 296 & 297 & 298 & 299 & 300 & 301 & 302 & 303 & 304 & 305 & 306 & 307 & 308 \\
\hline 0 & 97556 & 97523 & 97432 & 97437 & 97406 & 97337 & 97357 & 97317 & 97225 & 97269 & 97294 & 97200 & 97215 \\
\hline 0.2 & 97493 & 97478 & 97407 & 97404 & 97355 & 97277 & 97290 & 97242 & 97158 & 97179 & 97188 & 97105 & 97101 \\
\hline 0.4 & 97479 & 97455 & 97384 & 97373 & 97319 & 97234 & 97242 & 97191 & 97111 & 97120 & 97124 & 97037 & 97031 \\
\hline 0.6 & 97461 & 97430 & 97358 & 97347 & 97283 & 97199 & 97201 & 97146 & 97070 & 97072 & 97070 & 96969 & 96957 \\
\hline 0.8 & 97443 & 97403 & 97333 & 97319 & 97249 & 97159 & 97160 & 97100 & 97030 & 97017 & 97006 & 96913 & 96897 \\
\hline 1 & 97424 & 97378 & 97305 & 97289 & 97212 & 97123 & 97121 & 97060 & 96990 & 96967 & 96954 & 96854 & 96843 \\
\hline 1.2 & 97403 & 97353 & 97280 & 97258 & 97179 & 97085 & 97081 & 97011 & 96949 & 96919 & 96904 & 96802 & 96788 \\
\hline 1.4 & 97383 & 97329 & 97253 & 97230 & 97146 & 97053 & 97043 & 96976 & 96902 & 96875 & 96857 & 96745 & 96736 \\
\hline 1.6 & 97366 & 97303 & 97227 & 97202 & 97110 & 97020 & 97003 & 96935 & 96865 & 96825 & 96811 & 96697 & 96684 \\
\hline 1.8 & 97341 & 97276 & 97201 & 97169 & 97077 & 96992 & 96968 & 96892 & 96831 & 96786 & 96757 & 96653 & 96635 \\
\hline 2 & 97320 & 97252 & 97174 & 97140 & 97043 & 96959 & 96930 & 96850 & 96795 & 96743 & 96719 & 96608 & 96591 \\
\hline 2.2 & 97297 & 97228 & 97149 & 97109 & 97012 & 96928 & 96898 & 96811 & 96763 & 96700 & 96674 & 96564 & 96544 \\
\hline 2.4 & 97273 & 97200 & 97124 & 97080 & 96977 & 96896 & 96860 & 96780 & 96725 & 96666 & 96636 & 96523 & 96501 \\
\hline 2.6 & 97247 & 97176 & 97101 & 97054 & 96946 & 96864 & 96826 & 96742 & 96693 & 96623 & 96592 & 96478 & 96460 \\
\hline 2.8 & 97221 & 97149 & 97077 & 97026 & 96916 & 96832 & 96791 & 96703 & 96659 & 96586 & 96549 & 96438 & 96418 \\
\hline 3 & 97196 & 97123 & 97051 & 96996 & 96883 & 96806 & 96758 & 96669 & 96624 & 96549 & 96509 & 96396 & 96375 \\
\hline 3.2 & 97169 & 97097 & 97025 & 96966 & 96852 & 96774 & 96726 & 96627 & 96590 & 96512 & 96470 & 96356 & 96335 \\
\hline 3.4 & 97146 & 97067 & 96997 & 96934 & 96823 & 96741 & 96696 & 96598 & 96554 & 96479 & 96436 & 96313 & 96297 \\
\hline 3.6 & 97119 & 97038 & 96969 & 96906 & 96792 & 96713 & 96667 & 96565 & 96523 & 96443 & 96399 & 96279 & 96260 \\
\hline 3.8 & 97091 & 97012 & 96941 & 96879 & 96764 & 96684 & 96638 & 96531 & 96487 & 96411 & 96364 & 96241 & 96217 \\
\hline 4 & 97064 & 96995 & 96914 & 96849 & 96736 & 96654 & 96604 & 96499 & 96453 & 96379 & 96331 & 96209 & 96185 \\
\hline 4.2 & 97038 & 96954 & 96890 & 96821 & 96709 & 96624 & 96574 & 96468 & 96425 & 96343 & 96299 & 96179 & 96154 \\
\hline 4.4 & 97012 & 96928 & 96862 & 96794 & 96680 & 96598 & 96545 & 96435 & 96393 & 96311 & 96265 & 96139 & 96121 \\
\hline 4.6 & 96984 & 96900 & 96835 & 96766 & 96651 & 96568 & 96518 & 96406 & 96362 & 96283 & 96233 & 96110 & 96086 \\
\hline 4.8 & 96955 & 96869 & 96810 & 96741 & 96620 & 96537 & 96487 & 96375 & 96331 & 96248 & 96201 & 96082 & 96053 \\
\hline 5 & 96929 & 96842 & 96784 & 96713 & 96591 & 96509 & 96459 & 96344 & 96301 & 96216 & 96167 & 96047 & 96020 \\
\hline
\end{tabular}




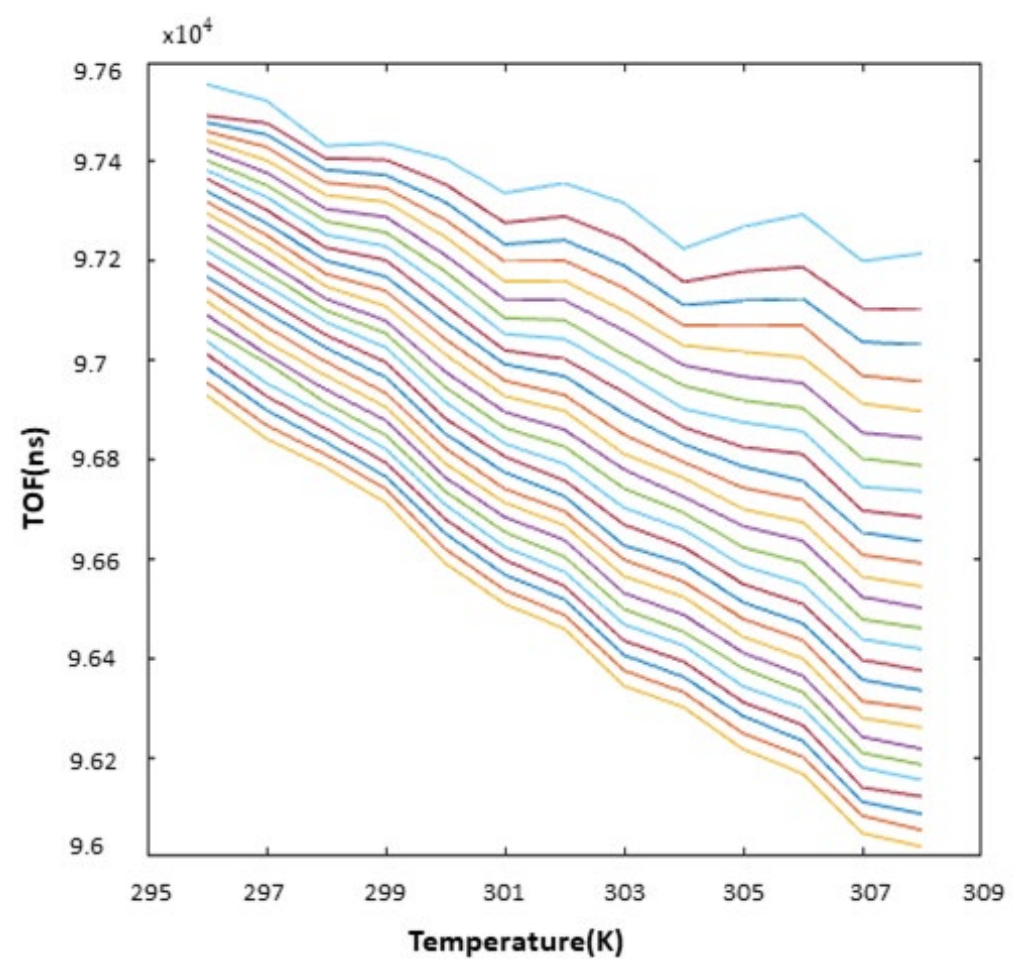

Fig. 6. Temperature - TOF Graph in the ethanol-water mixture. The TOF values were measured in nanoseconds, while the temperature values in Kelvin. The top plot shows the case when there is $0 \mathrm{ml}$ while the bottom plot when there is $5 \mathrm{ml}$ ethanol in the mixture and the other plots in between are for the TOF values in each $0.2 \mathrm{ml}$ ethanol increase in the mixture, respectively.

The top plot in the graph of Fig. 6 shows the case when there is $0 \mathrm{ml}$ while the bottom plot when there is $5 \mathrm{ml}$ ethanol in the mixture and the other plots in between are for the TOF values in each $0.2 \mathrm{ml}$ ethanol increase in the mixture, respectively. When the graph is analyzed, it is clear that there is a decrease in TOF values due to the change in the speed of sound while the amount of ethanol in the mixture does not change and the temperature is increasing. Likewise, the increase in the amount of ethanol in the mixture when the temperature is constant, the speed of sound has changed and the TOF values have decreased since the density of the liquid changes. Since the distance is constant, the speed of sound is calculated from TOF values at different temperatures and a curve is fitted for a smooth representation, Fig. 7 [25]. The top plot in the graph of Fig. 7 shows the case when there is $5 \mathrm{ml}$ while the bottom plot when there is $0 \mathrm{ml}$ ethanol in the mixture and the other plots in between are for the TOF values in each $0.2 \mathrm{ml}$ ethanol increase in the mixture, respectively. 


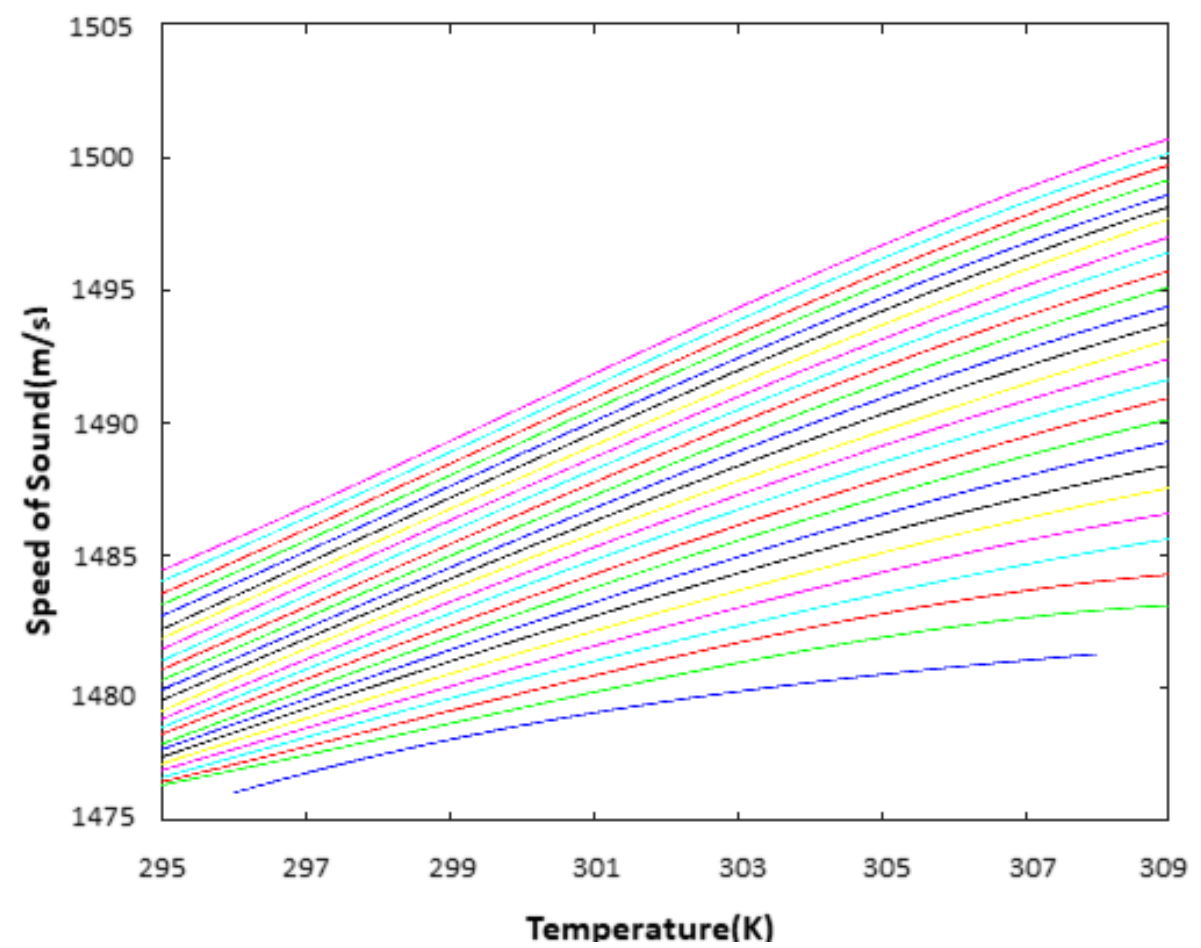

Fig. 7. Temperature - Speed of sound Graph in ethanol-water mixture. The speed in meter/seconds and temperatures in Kelvin. The top plot shows the case when there is $5 \mathrm{ml}$ while the bottom plot when there is 0 $\mathrm{ml}$ ethanol in the mixture and the other plots in between are for the TOF values in each $0.2 \mathrm{ml}$ ethanol increase in the mixture, respectively

As expected, the density of the mixture changed when the amount of ethanol is increased, and this resulted in an increase in the speed of sound discernibly between each case. Also it can be seen that a slight change in the ethanol concentration or the temperature, outcomes in a measurable change in the TOF.

For the performance evaluation of the system, half of the data is used for bilinear interpolation $(0.2-$ $0.6-1-1.4-1.8-2.2-2.6-3-3.4-3.8-4.2-4.6-5.0 \mathrm{ml})$ and the other half for testing $(0.4-0.8-1.2$ $-1.6-2-2.4-2.8-3.2-3.6-4-4.4-4.8 \mathrm{ml}$ ). The bilinear interpolation is applied with 0.01 steps for both added ethanol and temperature. Therefore, a lookup table for temperatures between $296-308 \mathrm{~K}$ and ethanol amount between $0.2-5 \mathrm{ml}$ with 0.01 steps is obtained. Therefore, on the contrary to the other studies, after measurement of the temperature and TOF values, the amount of ethanol contained in the mixture can be directly found from the lookup table (Fig.8) with high accuracy and precision without further mathematical calculations [18].

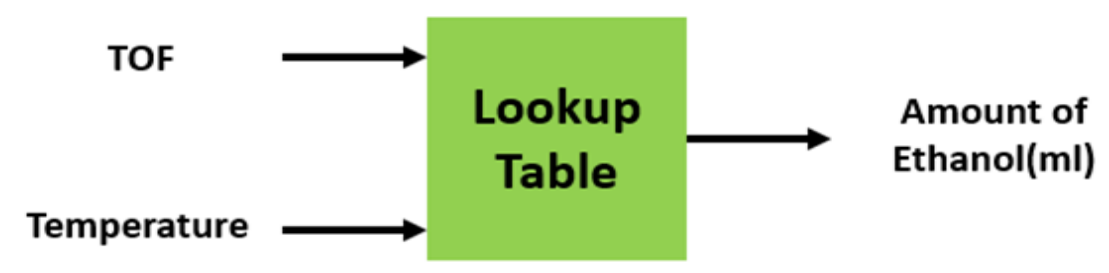

Fig.8. Block diagram of finding the amount of ethanol from lookup table. 
For the performance evaluation, the percentage relative error (PRE) and mean absolute percentage error (MAPE) is calculated using Eq. 10 and 11, respectively. The min, mean, and max absolute percentage error of the results are given at error bar graph in Fig. 9. From the results, it can be seen that the accuracy and as well as the precision of the system is high.

$$
\begin{aligned}
& \text { PRE }=\frac{\mid \text { Actual Values }- \text { Predicted Values } \mid}{\mid \text { Actual Values } \mid} \times 100 \\
& M A P E=\frac{\sum_{1}^{n} P R E(i)}{n} \text { (11) }
\end{aligned}
$$

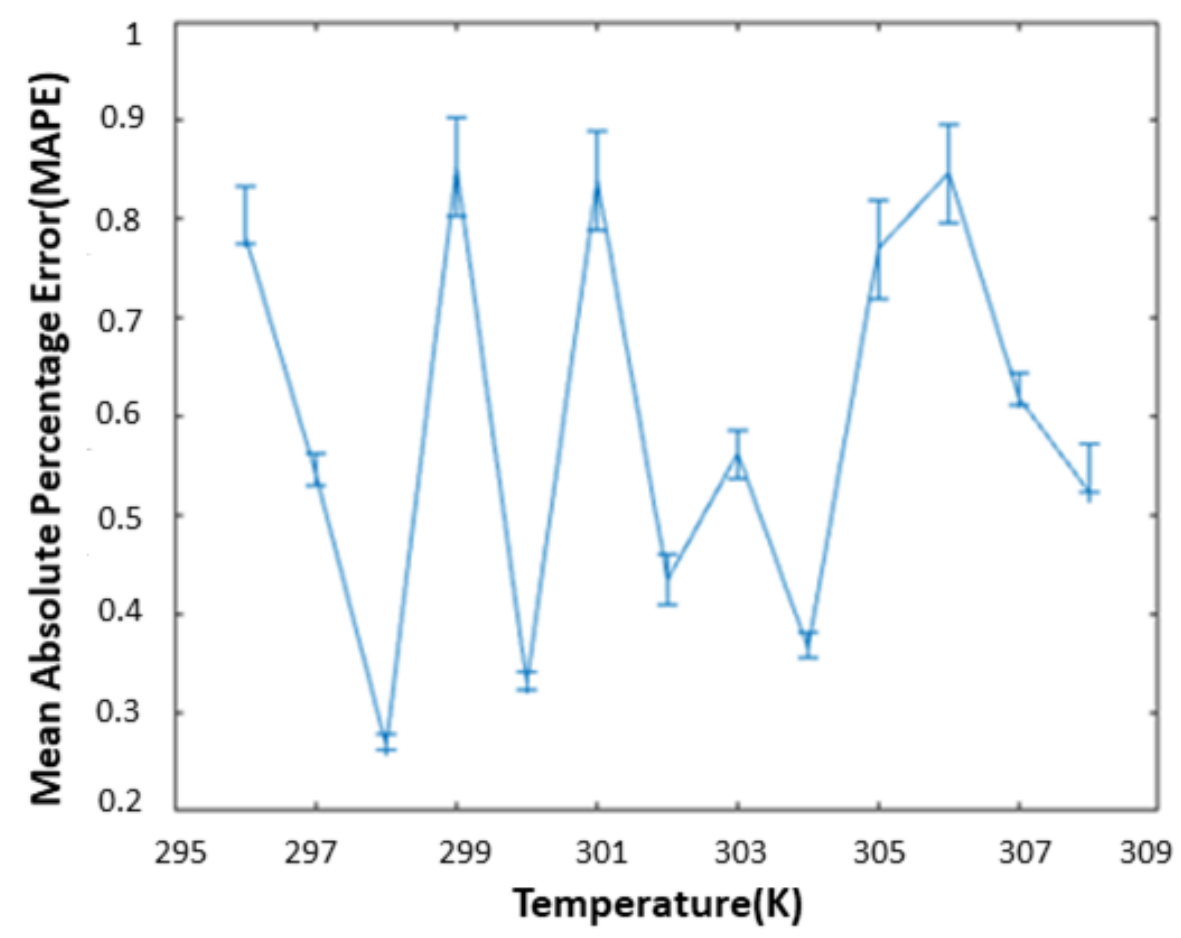

Fig. 9. Temperature - range of the mean absolute percentage error graph.

When the MAPE values in all measurements are examined, it is seen that these error values are very low. This is important because it shows that very low ethanol concentration changes can be detected with high accuracy in performed study. Thus, the study can be expanded in areas where ethanol content analysis is important such as food engineering, biomedical engineering, biochemistry etc. In addition to the mixture analysis studies, it can be performed in different studies such as process monitoring studies both industrial and biological fields or analysis of biological samples such as blood, urine, etc. Another advantage is that, on the contrary to the other studies, all the measurements can be performed and analyzed without a signal generator and an oscilloscope [25].

\section{Conclusion}

The ethanol is widely used in many industrial areas such as pharmaceutical, food, beverage, cosmetics, paint, medical, and automotive. Therefore, it is essential to analyze its concentration at the mixtures with high 
precision. The ultrasonic measurement method is an important and preferred method due to its accuracy, being cheap and noninvasive, and not having destructive effects on the material to be measured. In the study, the bilinear interpolation method is used to find the amount of ethanol contained in the mixture with high accuracy at different temperature values.

The currently available alcohol concentration measurement systems are invasive and/or use too many lab equipments that increase the total system cost and make them difficult to relocate and to use. Therefore, the main contributions of the study are high accuracy and precision with only a single board which makes it highly portable, and cost much less when compared with the currently available measurement systems.

Although the system is calibrated and tested with ethanol-water mixture, it can be used for any mixture that changes density related to the substance concentration, including different alcohols which are soluble in water (glycols, glycol ethers, etc.) or any other material (solid or liquid) which is soluble in alcohol or different liquid solvent.

The characteristics of the system indicate that the system has a broad and linear determination range for the ethanol starting from $0.552 \mathrm{~g} / \mathrm{L}$ and the detectability of the system is statistically within the $\mathrm{p}<0.05$ confidence interval. The standard deviation of the measurements is 0.21 . Therefore, the system with the advantages of not requiring extra equipment and mathematical calculations to find even very low concentrations of ingredients in the sample with high accuracy.

\section{References}

1. Chen, F., Yang, Z, Chen, Z. , Hu,J., Chen, C. and Cai J. J. of Mol. Liq. 2015, 209, 683-692.

2. Gowrisankar, M., Venkateswarlu, P., Sivakumar, K. and Sivarambabu, S. Arabian J. of Chem. 2017, $10, \mathrm{~S} 2625-\mathrm{S} 2636$.

3. Hevia, F., Cobos, A., González, J.A., de la Fuente, I.G. and Alonso V. J. of Solution Chem. 2017, 46, 150-174.

4. Salinas, R., Pla-Franco J., Lladosa, E. , and Montón, J.B. J. of Chemical \& Engineering Data, 2015, $60,525-540$.

5. Shekaari, H., Zafarani-Moattar, M.T., and Faraji, S. J. of Chemical \& Engineering Data, 2017, 62, 4187-4195.

6. Varfolomeev, M.A., Rakipov, I.T., Solomonov, B.N., and Marczak, W. J. of Chemical \& Engineering Data, 2016, 61, 1032-1046.

7. Zarei, H. and Keley, V. J. of Chemical \& Engineering Data, 2017, 62, 913-923.

8. Rowlinson, J.S. and Swinton, F. Liquids and liquid mixtures: Butterworths monographs in chemistry. 2013, Butterworth-Heinemann.

9. Park, R. West J. of Med., 1980, 133, 418.

10. Lieber, C.S. Alcohol.: Clin. and Exp. Res. 1991, 15, 573-592.

11. Giacomini, A. J. Acoust. Soc. of Am. 1947, 19, 701-702.

12. Meister, E.C., Measurement of the Temperature and Concentration Dependent Sound Velocity in Ethanol-Water Liquid Mixtures. 2015.

13. Widmark, E.M. Acta Med. Scand. 1919, 52, 87-164.

14. Akyilmaz, E. and Dinçkaya, E. Talanta 2003. 61, 113-118.

15. Heberle, I., Liebminger, A., Weimar, U., and Göpel, W. Sens. Actuators, B 2000, 68, 53-57.

16. Rahman, M.M., Jamal, A., Khan, S.B., and Faisal, M. Biosens. Bioelectron. 2011, 28, 127-134.

17. Azevedo, A.M., Prazeres, D.M.F., J.M. Cabral, and Fonseca, L.P. Biosens. Bioelectron. 2005, 21, 235 247.

18. Martin, K. and Spinks, D. Ultrasound in medicine \& biology, 2001, 27, 289-291.

19. Tong, J., Povey, M. Zou, X. Ward, B. and Oates, C. J. of Phys.: Conf. Ser. 2011, IOP Publishing.

20. Curry, A., Walker, G. and Simpson, G. Analyst, 1966, 91, 742-743.

21. Gonzalez-Rodriguez, J., Pérez-Juan, P. and M.L. De Castro, M.L. Talanta 2003, 59, 691-696.

22. Qi, X., Zhang, Y., Tu, R., Lin, Y., Li, X. and Q. J. Appl. Microbiol. 2011, 110, 1584-1591.

23. Kazys, R., Rekuviene, R., Sliteris, R., Mazeika, L. and Žukauskas, E. Ultrasonic technique for monitoring of liquid density variations. Vol. 86. 2015, 015003. 
24. Geier, D., Heermann, K. Hussein, M. and Becker, T. Eng. Life Sci. 2014, 14,433-441.

25. Vatandas, M., Koc, A.B. and Koc, C. Eur. Food Res. and Technol. 2007, 225, 525-532.

26. Smith, N.B.; Webb, A. Introduction to medical imaging: physics, engineering and clinical applications. Cambridge university press, 2010.

27. Hughes, J.F.; Van Dam, A.; Foley, J.D.; McGuire, M.; Feiner, S.K.; Sklar, D.F; Akeley, K. Computer graphics: principles and practice. Pearson Education, 2014.

28. Scott, A.J. and Knott, M. A cluster analysis method for grouping means in the analysis of variance. Biometrics, 1974, 507-512.

29. Ruxton, G.D. Behav. Chem. Eco. 2006, 17, 688-690.

30. Keskinoğlu, C., Analiz Ve Proses Takip Çalışmaları İçin Ultrasonik Cihaz Tasarımı Ve Üretimi (Ultrasound Device Design And Production For Analysis And Process Monitoring Studies), in Department of Biomedical Engineering. 2019, Cukurova University.

31.TDC1000-TDC7200EVMUser'sGuide, TDC1000-TDC7200EVM User's Guide , http://www.ti.com/lit/ug/sniu021a/sniu021a.pdf. 2015.

32. TDC1000 Ultrasonic Sensing Analog Front End (AFE) for Level Sensing, F.S., Concentration Sensing, and Proximity Sensing Applications, http://www.ti.com/lit/ds/symlink/tdc1000.pdf. 2015. 